Revista de Derecho de la Pontificia Universidad Católica de Valparaíso XXXVI (Valparaíso, Chile, 2011, $1^{\text {er }}$ Semestre)

[pp. 117 - 138]

\title{
LOS REMEDIOS AL INCUMPLIMIENTO CONTRACTUAL EN LOS PROYECTOS FRANCESES DE REFORMA DEL DERECHO DE CONTRATOS*
}

["The Remedies for the Breach of Contract in the French Projects on the Reform of the Contract Law"]

\section{Carlos Pizarro Wilson** Universidad Diego Portales, Chile}

\begin{abstract}
RESUMEN
El trabajo expone los fundamentos y las finalidades de una reforma al Derecho de contratos en los códigos decimonónicos inspirados en el Code Civil francés, para lo cual examina los proyectos de reforma concernientes elaborados en Francia, y explicitar cuáles serían los parámetros adecuados desde un punto de vista técnico-jurídico que deberían incidir en dicha tarea; en fin, confronta esos supuestos con los proyectos franceses en el ámbito del incumplimiento y remedios contractuales.
\end{abstract}

\begin{abstract}
This article puts forward the grounds and the purposes of a reform to the Contract Law in the nineteenth century codes, inspired on the French Code Civil; in order to do so, it examines the corresponding reform projects prepared in France and explains which would be the proper parameters from a technical juridical point of view, which would influence this task. In short, it compares these suppositions with the French projects in the scope of the breach and contractual remedies.
\end{abstract}

* Este artículo forma parte del proyecto FondeCyt Regular No 1100284: "Por una reforma a las reglas de incumplimiento contractual en el Código Civil". El autor agradece asimismo a la Fondation Maison des Sciences de l'Homme por haberlo beneficiado con la beca Hermès, que permitió una pasantía en la Universidad Paris II en el año 2009.

** Profesor investigador de la Facultad de Derecho de la Universidad Diego Portales, Santiago, Chile. Doctor en Derecho por la Universidad Paris II Panthéon-Assas. Dirección postal: República 105, Santiago, Chile. Correo electrónico: carlos.pizarro@ udp.cl 
Palabras Clave

Incumplimiento contractual - Remedios al Incumplimiento contractual - Reforma francesa del Derecho de contratos.

\section{KEYWORDS}

Breach of contract - Remedies to the breach of contract - French reform on Contract Law.

[RECIBIDo el 23 de marzo y APROBADo el 11 de abril de 2011].

\section{TRES PROYECTOS DE REFORMA AL DERECHO DE CONTRATOS EN FRANCIA}

La reforma al Derecho de los contratos ha sido un tema de actualidad en Francia desde la celebración del bicentenario del Código Civil de ese país. Tres propuestas han sido presentadas: la primera, del profesor Pierre Catala con un grupo de profesores de Derecho civil ${ }^{1}$; la segunda, de origen gubernamental, denominada "Proyecto de la Chancellerie"2; y la última, dirigida por el profesor François Terré, quizá la más lograda en sus aspectos técnicos, y que surgió como un conjunto de observaciones al "Proyecto de la Chancellerie", pero que, en definitiva, se transformó en una propuesta articulada distinta ${ }^{3}$. Estos proyectos de reforma abarcan todo el Derecho de los contratos e, incluso, se extienden a otros ámbitos del Derecho de las obligaciones, pero con énfasis en el ámbito del incumplimiento contractual. En este trabajo no haremos referencias al Derecho nacional, pues un ejercicio comparativo ya ha sido planteado en otros. Ahora el objetivo es exponer la corriente francesa que pretende modificar el Code Civil en el ámbito del Derecho de los contratos, y mostrar las diferencias, dudas y críticas que han merecido en la propia doctrina francesa.

Los tres esfuerzos o propuestas de reforma al Derecho de los contratos en Francia se enmarcan en un movimiento sucesivo de adaptación del Derecho francés a la sociedad contemporánea. Fue a propósito del bicentenario que la inquietud comenzó a manifestarse ${ }^{4}$. En lugar de la complacencia por tener un código vigente después de doscientos años, se realizó una mirada crítica al

\footnotetext{
${ }^{1}$ Catala, P., Avant-projet de réforme du Droit des obligations et de la prescription (Paris, Ministère de la Justice, La Documentation Française, 2006).

${ }^{2} \mathrm{Si}$ bien han existido varias versiones, algunas oficiales y otras que circulan entre los pasillos universitarios, he utilizado la versión que me hizo llegar el profesor Thomas Genicon correspondiente a 2010.

${ }^{3}$ Terré, F., Pour une réforme du Droit des contrats (Paris, Dalloz, 2009).

${ }^{4}$ Las dos obras de referencia son: AA. VV., Le Code Civil 1804-2004, Livre du Bicentenaire (Paris, Dalloz-Litec, 2004); AA.VV., 1804-2004, Le Code Civil, un passé, un présent, un avenir (Paris, Dalloz, 2004).
} 
Derecho positivo en innumerables coloquios y congresos. Si bien se trató de una fiesta en honor al Code, no faltaron las miradas críticas para un Derecho en grandes parcelas con un cierto anquilosamiento. La excepción no fue el Derecho de las obligaciones.

La virtud que se reclama a un Derecho de la familia continental es compilar en un texto legal el Derecho vigente que constituya la expresión de las reglas que nos gobiernan 5 . Para nadie es un misterio que el Code Civil y, en general, los códigos decimonónicos han ido perdiendo terreno en la aplicación de sus normas, y que la superación de lagunas e, incluso, la creación de reglas en forma pretoriana ha sido obra de la jurisprudencia judicial. Si reclamamos para el Derecho continental esa virtud de seguridad y expresión del Derecho positivo en nuestros textos legales, la reforma se hace imperativa en un ámbito como el Derecho de los contratos, en que para entender cómo se solucionan los problemas jurídicos que arroja esta materia no basta el solo código, sino que es imperativo conocer la jurisprudencia y la doctrina.

Este fenómeno es especialmente palpable en el Derecho francés. En Chile resulta menos intenso, en que una jurisprudencia conservadora suele continuar apegada a textos antiguos, a pesar de que la solución ofrecida por ellos no sea la más coherente o apropiada ${ }^{6}$. De ahí entonces una razón relevante para modificar el Code, sus reglas que tanto elogio merecieron ya no responden al tráfico contractual contemporáneo 7 .

Otra razón que atraviesa los esfuerzos de reforma en el Derecho francés de los contratos radica en el movimiento codificador a nivel europeo y las reformas implementadas en otros países de la Unión Europea en la materia,

${ }^{5}$ Sobre esto: GRIMALDI, M., El Derecho continental frente a la mundialización (traducción castellana de Sara Moreno), en Pizarro Wilson, C. (editor), Derecho y Economía. Cátedra por el Derecho Continental (Santiago, 2011) (en prensa).

${ }^{6}$ Vidal Olivares, A., El incumplimiento de obligaciones con objeto fungible y los remedios del acreedor afectado. Una relectura de las disposiciones del "Código Civil" sobre incumplimiento, en Guzmán Brito, A. (editor), El Código Civil de Chile (18552005). Trabajos expuestos en el congreso internacional celebrado para conmemorar su promulgación. Santiago, 3-6 de octubre de 2005 (Santiago, LexisNexis, 2007), pp. 495 ss.

${ }^{7} \mathrm{El}$ debate acerca del Código europeo o las reformas locales ha quedado algo superado. Para una confrontación de ideas, véase: Lequette, Yves, Vers un Code Civil européen? en Pouvoirs, en Revue Française d'Études Constitutionnelles et Politiques, 107 (2003), pp. 97-126 [disponible en http://www.revue-pouvoirs.fr/Vers-un-Code-civileuropeen.html, visitada el 3 de enero de 2011]; D’une célébration à l'autre (1904-2004), en Université Paris II Panthéon-Assas (editor), 1804-2004 Le Code Civil, un passé, un présent, un avenir (Paris, Dalloz, 2004), pp. 9 ss.; en la otra orilla,: TAllon, D., Vers un Droit européen du contrat? en Mélange A. Colomier (Paris, Litec, 1993), p. 485; EL MISMo, Les principes pour le Droit européen du contrat, en Défrenois (2000), p. 683; EL мismo, Grandeur et décadence du Code Civil français, en Mélanges Marcel Fontaine (Paris, Larcier, 2007), p. 279. 
en particular, en Holanda y Alemania, quizá con mayor énfasis en este último país, cuyo efecto una vez aprobada la ley de modernización del Derecho de las obligaciones impactó con intensidad en España y algunos comentarios tuvo en Francia. Con esta reforma, se pensó, Alemania se transformaba en un Derecho más competitivo como modelo de reforma para otros países, pero sobre todo para los procesos de armonización a nivel europeo en una severa competencia por imponer la propia identidad jurídica y, al mismo tiempo, exportarla a otros sistemas legales ${ }^{8}$.

Si bien ya nadie piensa, por el momento, en la viabilidad de un código europeo, las directivas y reglamentos en el terreno del Derecho contractual no cesan de multiplicarse, debiendo acordarse reglas que respondan a las diversas familias jurídicas que componen la Unión Europea. Con un Derecho viejo de 200 años Francia se veía disminuida en esta batalla por el Derecho o, incluso, podríamos decir, por la cultura jurídica. El tema es aún más sensible para Francia, cuyo Código fue un bien exportado a numerosos rincones del planeta, siendo su influencia palpable hasta hoy ${ }^{9}$. Esta pérdida de presencia frente a la "Common law", no sólo en la contratación comercial internacional, sino también en las reformas de países fuera de la comunidad europea justificaba construir un Derecho más competitivo y atractivo para adoptarse por otros países.

La anterior razón de los proyectos de reforma incide en una tercera causa, cual es la protección o resguardo de la identidad jurídica local. Aquí se manifiesta un fenómeno muy diverso entre el Derecho español y el francés y, podríamos agregar, nuestros sistemas legales en relación a Francia. El Derecho francés tiene una historia e identidad muy fuerte que ha mantenido no sólo sus leyes civiles, sino también su doctrina impermeable, si bien no en forma total, pero en gran medida, distante a las influencias foráneas. Es un Derecho civil que se ha exportado a través de sus códigos y doctrina, pero que recibió, hasta ahora, una influencia extranjera más bien moderad ${ }^{10}$. En cambio, España siempre ha sido un país en su Derecho abierto a la influencia externa, en particular el Derecho alemán ${ }^{11}$. Así lo indica en forma explícita la

${ }^{8}$ Quizá el esfuerzo más significativo en Francia sea la creación de la Fondation pour le Droit Continental, cuyo director académico es el reconocido profesor Michel Grimaldi. Sobre sus acciones consultar: www.fondation-Droitcontinental.org [visitada el 15 de marzo de 2011].

${ }^{9}$ Grimaldi, M., L'exportation du Code Civil, en Pouvoirs. Revue Française d'études Constitutionnelles et Politiques, 107 (2003) [disponible en http://www.revue-pouvoirs. fr/L-exportation-du-Code-civil.html, visitada el 3 de enero de 2011].

${ }^{10}$ Algunas pistas para entender esto en: Jestaz, Ph. - Jamin, C., La doctrine (Paris, Dalloz, 2003).

${ }^{11}$ Díez-Picazo, L, Reforma de los Códigos y Derecho europeo, en Anuario de Derecho Civil, 56 (2003) 4, p. 1565 ss.; EBERs, M., La nueva regulación del incumplimiento 
exposición de motivos del proyecto de reforma español en esta misma materia, que alude a la necesaria modernización siguiendo al Derecho alemán ${ }^{12}$. Nada de eso es tan válido para los juristas franceses quienes se precian de un éthos jurídico suficiente para autogobernarse. Los procesos de unificación europeos han sido resistidos por una parte importante de la doctrina francesa, quizá quien mejor lo muestra y con gran talento es el profesor Yves Lequette $^{13}$, mientras que una minoría comenzó a admitirlo y otros ya se inclinan por abrir el Derecho francés a la influencia europea ${ }^{14}$. Son esas tensiones las que han marcado el proceso de creación de los proyectos de reforma. Como lo ha sugerido Denis Mazeaud, es posible verificar en el "Proyecto Catala" una resistencia a lo foráneo, un esfuerzo de adaptar el Derecho codificado más bien a la evolución jurisprudencial propia a Francia. Un último estertor para mantener incólume, aunque moderno, el afamado Code Civil. Podríamos llamarlo un intento de maquillaje que permita a ese cuerpo legal verse más joven, pero sin ir a cuestionar su estructura o las instituciones que lo componen, sino de una manera bastante tangencial. Sintomático resulta que dicho trabajo fue fruto de una parte de la doctrina, pero compuesta de manera exclusiva por profesores universitarios. El modelo, con algo de ironía, es más académico que económico ${ }^{15}$.

La situación es diversa tratándose del proyecto denominado "de la Chancellerie" que surgió desde el mundo judicial bajo el alero de una profesora comparatista, recibiendo a los profesores de Derecho civil en audiciones en que emitían sus opiniones, mas sin participar realmente en la redacción de los textos legales ${ }^{16}$. Este proyecto marca una apertura significativa al Derecho común europeo al considerar sin remilgos los instrumentos internacionales y transnacionales relativos al Derecho de los contratos. Es el mismo Mazeaud quien lo dice en términos elocuentes: mientras el "Proyecto Catala" manifiesta la reacción, el proyecto gubernamental constituye la apertura y aquél

contractual en el BGB, tras la Ley de modernización del Derecho de obligaciones de 2002, en Anuario de Derecho Civil, 56 (2003) 4, pp. 1565 ss.

${ }^{12}$ Propuesta de Modernización del Código Civil en materia de obligaciones y contratos, en Boletin de Información (Madrid, Ministerio de Justicia, 2009), p. 11.

${ }^{13}$ Véase la nota 7. En particular sobre el "Proyecto de la Chancellerie": GHOzI, A. Lequette, Y., La réforme du Droit des contrats, en Dalloz, 37 (2008), p. 2609 ss.

${ }^{14}$ El mejor ejemplo es el "Proyecto de la Chancellerie" y aquel coordinado por el Profesor François Terré. Ambos admiten una influencia de los Principios del Derecho europeo de los contratos.

${ }^{15}$ Mazeaud, D., La réforme du Droit français des contrats : trois projets en concurrence, en Liber amicorum Christian Larroumet (Paris, Economica, 2009), pp. 256 ss.

${ }^{16}$ Véase: CABRILlaC, R., Le projet de réforme du Droit des contrats, en La semaine Juridique, édition générale, 40 (2008), I, p. 190; GHestin, J. y AA.VV., Observations sur le projet de réforme du Droit des contrats, en Petites Affiches, 31 (2009), pp. 8 ss. 
patrocinado por François Terré es la ruptura con un modelo si podemos decir estrictamente a la francesa ${ }^{17}$.

Como era de esperarse, la doctrina francesa se incendió en un debate intenso y prolongado sobre estos proyectos, bastante tinta, quizá demasiada, se ha derramado ya para explicar los diversos proyectos y no se vislumbra una posibilidad cierta de reforma, más bien por falta de apoyo político que por otra cosa. Mientras tanto la doctrina francesa seguirá analizando sus proyectos y quien nos dice que no surjan otros. A la época en que Françios Gény escribió su monumental obra sobre el método, los civilistas que le siguieron debían tener un manual o tratado personal, apartándose del estudio denominado "exegético" de artículo por artículo; hoy más bien la fiebre que inunda la civilística francesa es tener una reforma al código con su nombre. Eso sí, la grandeza de la doctrina francesa está ahí, en reconocerse como un cuerpo en permanente diálogo y crítica constante con sus reglas e ideas. Son estas propuestas que ahora se analizan a propósito del incumplimiento y las reacciones que puede adoptar el acreedor a través de la sanción o remedio al mismo.

Si observamos al Derecho local, con un código casi tan vetusto como el francés, las reflexiones precedentes tienen un sentido. Se trata de ordenamientos jurídicos con menos identidad o con una doctrina con menor arraigo a su cultura jurídica y, por lo mismo, menos refractaria a mirar los procesos de cambio legislativo en el Derecho comparado ${ }^{18}$. Es usual que leyes extranjeras sean tomadas in corpore para adaptarlas o maquillarlas a nuestra realidad. Por lo mismo las interrogantes sobre un proceso de cambio en el Derecho de los contratos en países como Chile, si bien no constituyen una necesidad imperiosa, pues las reglas aún funcionan, al igual que en otros sistemas continentales, es interesante indagar la posibilidad de recoger el debate en el Derecho francés, realizar un ejercicio crítico del Derecho local, abriéndose a la idea de mejorarlo o reformarlo.

Siendo una materia extensa aquella dedicada a los contratos y aún más al Derecho de las obligaciones, me concentraré en lo relativo al incumplimiento contractual. En una primera parte indicaré las razones jurídicas, de técnica legal, que justifican una revisión del Derecho de los contratos (II), lo que me parece es pertinente no sólo para el Derecho francés, sino también para el Derecho chileno. En segundo término, abordaré las reglas en particular dedicadas en las propuestas al incumplimiento del contrato y sus consecuencias (III).

${ }^{17}$ Mazeaud, La réforme, cit. (n. 15), pp. 263 ss.

${ }^{18}$ Una explicación a la diversa realidad en el cuerpo doctrinal local en: Pizarro Wilson, C., En defensa de la Dogmática: los civilistas hoy, en Carvajal, Patricio (editor), Libro homenaje a Alejandro Guzmán Brito (2011), en prensa. 


\section{Justificación de la Reforma al DeRecho de los contratos DEL "Code Civil"}

Frente al incumplimiento de una obligación de naturaleza contractual, las "sanciones" o "remedios" 19 de que provee el ordenamiento jurídico al acreedor insatisfecho aparecen como diversas y bastante dispersas en los códigos de origen decimonónicos. En el Code Civil el tratamiento de esta cuestión ha sido considerado defectuoso, cuya regulación es dispersa e inorgánica. El mismo fenómeno es posible constatar en el Código Civil chileno ${ }^{20}$.

Para el Derecho francés, el cumplimiento forzado o ejecución en naturaleza se regula a propósito de la obligación de dar una especie o cuerpo cierto, la resolución por incumplimiento aparece en el ámbito de la condición, la suspensión del cumplimiento y la reducción del precio no se contemplan como remedios contractuales. La única parcela un tanto más organizada es aquella relativa a la indemnización de perjuicios, pero que no ha cesado de suscitar complejas interrogantes que aparece necesario esclarecer, partiendo por la idea de unificar ambos estatutos de responsabilidad o mantenerlos en estancos apartados. Se trata de uno de los debates, al menos teóricos, más interesantes en la doctrina francesa de la década de los $90^{21}$.

En los sistemas inspirados en el Code, no siempre resulta fácil determinar qué acción debe intentar el acreedor. Tampoco es claro si entre las diversas sanciones existe alguna jerarquía o regla de prioridad. ¿Está el acreedor en caso de incumplimiento compelido a requerir la ejecución forzada? O puede según su interés escoger la indemnización de perjuicios. ¿Qué límites establecer para el ejercicio de las sanciones al incumplimiento?

De otra parte, la clasificación entre obligaciones de dar, hacer y no hacer,

${ }^{19}$ El uso de la expresión "remedios", que ha impulsado una parte importante de la doctrina española a través de sus discípulos locales merece un análisis. Sobre la cuestión y los problemas que suscita adoptar esta terminología sin la necesaria tarea previa de conocer cuál es el sentido y alcance en la "Common law", lo que mostraría que las virtudes asignadas a esta expresión no serían tales. La sistematización de las acciones a favor del acreedor en caso de incumplimiento sería un "mito" en el Derecho anglosajón, cubriendo esta expresión diversas cuestiones sin un verdadero consenso. Véase: Laithier, Y. M., Étude comparative des sanctions de l'inexécution du contrat (Paris, LGDJ, 2004), pp. 9 ss.

${ }^{20}$ Así ya ha sido dicho, Pizarro Wilson, C., Hacia un sistema de remedios al incumplimiento contractual, en GuZMÁn BRITO, Alejandro (editor científico), Estudios de Derecho Civil (Santiago, LexisNexis, 2008), III, pp. 395 ss.

${ }^{21}$ Rémy, Ph., L'inexécution du contrat, en Terré, F., Pour une réforme du Droit des contrats (Paris, Dalloz, 2008), p. 253. Antes, el célebre artículo de Tallon, D., L'inexécution du contrat : pour une autre présentation, en Revue Trimestrelle de Droit Civil. (1994), pp. 223 ss. 
con preeminencia de aquellas de especie o cuerpo cierto, a partir de las cuales se construye el sistema de incumplimiento en estos códigos. ¿Mantiene su vigencia? ¿Cómo aplicarlo con coherencia en un mercado creciente de obligaciones genéricas y de prestación de servicios? Ya veremos que no están contestes los Proyectos en este terreno ${ }^{22}$.

Otras sanciones o remedios al incumplimiento, no están previstas en los códigos del siglo XIX. Así ocurre con la reducción del precio, cuya pertinencia es posible aún discutir, sobre todo en perspectiva de su utilidad práctica. Esta sanción, al menos no aparece recogida de manera sistemática, sino sólo a propósito de los vicios ocultos por la vía de la acción quanti minoris. La solución al problema de la no conformidad, cuya presencia origina problemas severos de concurso de acciones y su relación con la ejecución forzada. La suspensión del cumplimiento tampoco está prevista, o sólo mediante un esfuerzo interpretativo, para los códigos chileno y colombiano ha podido construirse una excepción de contrato no cumplido a partir de la regulación de la mora que no ha estado exenta de conflictos a la hora de resolver el problema del incumplimiento recíproco. Esto ha ocurrido siguiendo la doctrina radiocanal francesa.

Pareciera necesario, y esto no es una novedad, sistematizar las sanciones en estos códigos frente al incumplimiento contractual. La interrogante es cómo lograrlo, y aparecen innumerables pistas en los tres proyectos en análisis.

\section{REMEDIOS AL INCUMPLIMIENTO CONTRACTUAL}

EN LOS PROYECTOS DE REFORMA

La verificación de los supuestos que debieren concurrir en una reforma a propósito del incumplimiento del contrato exige analizar la estructura en que aparecen recogidos y las opciones que se establecen respecto de cada uno de los remedios propuestos.

1. Estructura de las reglas del incumplimiento y sus sanciones.

a) En relación a la forma de abordar la materia, como es usual el "Proyecto Catala”, mantiene una estructura cercana al Code, aunque mejorada,

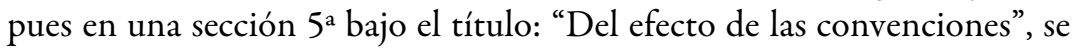
ocupa del incumplimiento y la resolución, pero no concurre un tratamiento sistemático del cumplimiento forzado y, quizá, un tema conflictivo, las reglas de indemnización por incumplimiento quedan en el ámbito de la responsabilidad civil, con un conjunto de reglas comunes y otras especiales. De ahí que en la misma presentación se afirme que ese anteproyecto no

${ }^{22}$ VIDAL, cit. (n. 6), pp. 495 ss. 
propone un código de ruptura, sino de ajuste ${ }^{23}$. No hubo cambios sustantivos en la "arquitectura" ${ }^{24}$, y se mantiene la distinción entre obligaciones de dar, hacer y no hacer a efectos del cumplimiento ${ }^{25}$. En relación al incumplimiento se consagró una sección $5^{\mathrm{a}}$ en el capítulo $3^{\circ}$ relativo al efecto de las obligaciones, titulado: De l'inexécution des obligations et de la résolution du contrat, cuyo contenido intenta resolver los problemas de lagunas y avances jurisprudenciales en la materia, aunque dejando aparte la indemnización de perjuicios. Se refiere a la excepción de contrato no cumplido en los contratos sinalagmáticos para fijar el ámbito de aplicación de la institución y a la fuerza mayor como causal transitoria o definitiva de exoneración en la hipótesis de incumplimiento. La elección a favor del acreedor para exigir la ejecución forzada o la resolución, además de la indemnización de perjuicios, aunque estos últimos pueden ir o no en conjunto con alguna de las otras dos alternativas según el caso (artículo 1158). Se incorpora la resolución unilateral con determinadas condiciones de aplicación, cuya opción puede ser controvertida a posteriori ante los tribunales. Se explicita la posibilidad de las partes de pactar una cláusula resolutoria, acogiendo la necesidad de precisar los incumplimientos resolutorios y los efectos (artículo 1159). Se acoge la resolución parcial (artículo 1160). Se consagra en forma explícita el efecto de la resolución, distinguiendo si produce efectos sólo para el futuro o con efecto retroactivo -artículo 1160-1.

En síntesis, la estructura del proyecto, marcado por su carácter académico, intenta sistematizar las opiniones de la doctrina con las soluciones de la época en la jurisprudencia francesa, con el propósito de mantener el "espíritu" del código, pero al mismo tiempo completar las lagunas que presenta en la materia.

b) El "Proyecto de la Chancellerie" sigue una estructura compartida en los instrumentos internacionales y propuestas de reformas. Comienza la apertura a Europa en forma más franca y decidida. En el capítulo $10^{\circ}$ acerca del incumplimiento se trata la materia, partiendo por la facultad del acreedor de escoger la sanción frente al incumplimiento -artículo 161-, la excepción de contrato no cumplido (artículo 162), la excusa de fuerza mayor (artículo 163), para luego distinguir entre las diversas sanciones, partiendo por el cumplimiento forzado (artículos 164 a 166); la resolución, distinguiendo entre la cláusula resolutoria, la resolución unilateral y aquella judicial; los efectos

${ }^{23}$ Catala, cit. (n. 1), p. 13. La presentación de la parte relativa al "effet des conventions, interprétation, qualification (artículos 1134 à 1143) estuvo a cargo del profesor Alain Ghozi.

${ }^{24}$ Catala, cit. (n. 1), p. 46.

${ }^{25}$ Catala, cit. (n. 1), p. 50, presentación por los profesores Laurent Leveneur y Hervé Lécuyer, lo que quedó establecido en los artículos 1152 a 1153-1. 
según el contrato sea de cumplimiento instantáneo o de ejecución sucesiva escalonada; ciertas condiciones para la aplicación de la cláusula resolutoria y la resolución unilateral, indicando que siempre podrá recurrirse a los tribunales para obtener la resolución judicial; por último se reproducen los artículos relativos a la responsabilidad contractual sin modificaciones. Aparece un tratamiento más coherente del incumplimiento y las sanciones.

c) Sin duda el "Proyecto Terré" es el más logrado, inspirado en la necesidad de claridad y coherencia, sigue el modelo de los "Principios Unidroit", Lando y DCFR, aunque sin dejar de lado la doctrina y jurisprudencia francesas.

Se trata de la forma adecuada de exponer las reglas dedicadas al incumplimiento, pues alejada de esfuerzos académicos, entrega al justiciable una mayor claridad y coherencia que potencia el conocimiento de esas normas. No se trata de un plan académico, sino de una exposición práctica.

d) Los tres proyectos abordan la noción de incumplimiento en forma sencilla, aludiendo a la falta total de cumplimiento o al cumplimiento imperfecto. Asimismo, en ellos se enlaza el incumplimiento con la opción del acreedor para escoger la sanción adecuada, aunque según se verá con matices. Las reglas respectivas en todos los proyectos se limitan a señalar que la parte a quien afecta la falta de ejecución o si lo ha sido en forma imperfecta, tiene la elección, según las circunstancias, de perseguir la ejecución forzada, la resolución judicial o aquella unilateral o la indemnización de perjuicios. El "Proyecto Terré" agrega otros remedios en forma más sistemática que los otros, la suspensión de la ejecución de su propia obligación y reducir el precio. Si bien tanto el "Proyecto Catala" como aquel de la Chancellerie comprenden la excepción de incumplimiento de contrato, no así la reducción del precio.

En todo caso, el interés de estos preceptos que aluden a la noción de incumplimiento total o parcial consiste en asociar su concurrencia con los distintos remedios o sanciones que puede emplear el acreedor insatisfecho. Se alcanza una noción de incumplimiento transversal para los remedios contractuales. La satisfacción de la idea primaria de noción única de incumplimiento, a partir del cual se genera el elenco de remedios a favor del acreedor.

\section{Los remedios al incumplimiento contractual.}

La articulación de los remedios se afirma en los tres proyectos de reforma a partir de la noción de incumplimiento. El tratamiento de los remedios en particular muestra las diferencias y opciones que pueden plantearse en la materia.

a) La ejecución forzada del contrato. La ejecución forzada del contrato constituye una sanción transversal frente al incumplimiento con- 
tractual ${ }^{26}$. El juez impone al deudor el cumplimiento de su compromiso. En el "Proyecto Catala" aparece una opción marcada por esta sanción al incumplimiento contractual. Se asocia el cumplimiento forzado a la fuerza obligatoria del contrato. Sin embargo, no se trata de una directriz estricta, pues se admite la facultad de retractarse y la resolución unilateral ${ }^{27}$. En varias oportunidades el proyecto afirma la opción por la ejecución forzada ${ }^{28}$. Se trata de la "sanción de principio", cuyo límite se encuentra en la imposibilidad, la cual puede ser material o jurídica ${ }^{29}$. El proyecto acoge en forma explícita la posición de la Corte de casación francesa, lo que está en consonancia con la mayoría de la doctrina francesa ${ }^{30}$. En relación a las obligaciones de hacer la declaración es elocuente, al disponer el artículo 1154 que este tipo de obligaciones se ejecuta en lo posible en naturaleza, con el límite que la obligación presente un carácter personalísimo y, otro límite, queda dispuesto por la exclusión de la coerción atentatoria a la libertad o a la dignidad del deudor. Es probable que estos límites a la ejecución forzada puedan reducirse sólo a la imposibilidad, apareciendo la distinción más pedagógica que práctica. Sin perjuicio que el contenido de estos límites deben ser integrados por los jueces y la discusión si la dignidad es pertinente o, más bien, acarrearía la nulidad del contrato por ser contraria la obligación al orden público ${ }^{31}$. Sin duda la regulación del cumplimiento forzado en el "Proyecto Catala" desdeñó consideraciones económicas al obviar el límite de su procedencia para la hipótesis en que su ejecución significara un costo desmesurado para el deudor ${ }^{32}$. Tampoco se admite el deber de minimizar el daño en relación al cumplimiento forzado, distanciándose de los instrumentos internacionales ${ }^{33}$. Esta última ausencia vigorosa el cumplimiento forzado, pues aún para

${ }^{26}$ Para una visión de conjunto en Europa: AnCel, P. - FAuvareue-Cosson, B. - Wintgen, R., Regards comparatistes sur l'exécution forcée en nature, en Revue des Contrats, 2 (2006), pp. 529 ss.

${ }^{27}$ LAITHIer, Y.-M., L'exécution des obligations contractuelles, en CARTWRIGHT, John - Vogenauer, Stefan - Whittaker, Simon, Regards comparatistes sur l'avantprojet de réforme du Droit des obligations et de la prescription (Paris, Société de Législation Comparée, 2010), p. 144.

${ }^{28}$ Artículos 1152 inciso $3^{\circ}, 1154$ inciso $1^{\circ}, 1154$, parte final y 1155 inciso $3^{\circ}$, a propósito de la distinción entre obligaciones de dar, hacer y no hacer.

${ }^{29}$ LAithier, cit. (n. 27), p. 152.

${ }^{30}$ Véanse : Terré, F. - Simler, Ph. - Lequette, Y., Droit civil. Les obligations (Paris, Dalloz, 2005), pp. 1037 ss.; Malaurie, Ph. - Aynès, L. - Stoffel-Munck, Ph., Les obligations (Paris, Defrénois, 2009), pp. 619 ss.

${ }^{31}$ LAithier, cit. (n. 27), p. 155.

${ }^{32}$ Laithier, cit. (n. 27), p. 156.

${ }^{33}$ Artículo 9:102 letra d) de los PEDC. relativo a las obligaciones no dinerarias; sobre esto: Díez-Picazo, L, - Roca Trias, E. - Morales, A. M., Los principios del Derecho europeo de contratos (Madrid, Civitas, 2002), p. 345. Para Francia, véase : Jo- 
el caso en que el acreedor pueda realizar un cumplimiento por equivalencia -operación de reemplazo- o algún otro remedio le sea satisfactorio, tendrá siempre en sus manos forzar al deudor a cumplir. Por último, un aspecto en que no ha existido la preocupación doctrinal adecuada, el proyecto omite toda referencia a la posibilidad de las partes de convenir sobre las condiciones y efectos del cumplimiento forzado ${ }^{34}$.

Podemos concluir que en relación al cumplimiento forzado, el "Proyecto Catala" no innova, sino que retrata más bien el estado actual del Derecho positivo francés, incluída la jurisprudencia de la Corte de casación, sin considerar límites en perspectiva más económica -costo irracional o minimización del daño-, ni tampoco el aspecto convencional que puede darse a propósito de esta sanción. Estas ausencias en el articulado son criticables, pues aparecen como una necesidad en el modelo del nuevo Derecho de la contratación. Además, la primacía de la ejecución forzada en ese mismo modelo no constituye un dogma, sino que pasa a ser la sanción en naturaleza otro remedio a favor del interés del acreedor.

En el "Proyecto de la Chancellerie" persiste la primacía de la ejecución forzada. Aparece asociada a los principios directores, en particular el artículo 17 que en forma expresa luego de exponer la fuerza obligatoria, señala que cada parte podrá exigir de la otra la ejecución de su obligación tal como fue prevista en el contrato. Luego, a propósito de la distinción entre las obligaciones de dar, hacer y no hacer. En el artículo 111 se estipula que esas obligaciones se ejecutan en principio en naturaleza. Se recoge también la elección a favor del acreedor entre los distintos remedios. A diferencia del "Proyecto Catala", el artículo 164 amplía los límites a la ejecución forzada al considerar como obstáculo no sólo la imposibilidad, sino también para el caso que el costo sea manifiestamente irracional. En cambio se suprime la referencia a la libertad y dignidad del deudor. Se puede observar en esta modificación la influencia de los PEDC. ${ }^{35}$. Esta excepción a la ejecución

URDAIN, P., Présentation des dispositions de l'avant-projet sur les effets de la responsabilité, en Revue des Contrats, 7 (2007) 1, p. 141 ss.

${ }^{34}$ LAITHIER, cit. (n. 27), p. 158. El autor desarrolla el tema analizando la viabilidad de una cláusula impositiva del cumplimiento forzado o, por el contrario, una que la excluya en forma perentoria.

${ }^{35}$ No debe olvidarse que en la jurisprudencia francesa se habían dado situaciones excesivas a propósito de la primacía de la ejecución forzada; al respevto, véanse: PASCAL, Ancel y otros,, Points de vue convergents sur le projet de réforme du Droit des contrats, en Semaine Juridique, 48 (2008) 1, pp. 18 ss., en particular, p. 22, en que se hace referencia al fallo de los 33 centímetros. A favor de una apreciación del carácter adecuado de la sanción: GRIDEL, J. P., Les sanctions civiles de l'inexécution du contrat imputable au débiteur: état des lieux, en Semaine Juridique, 21 (2008) 1, p. 13, en particular, p. 15. Por un visión neutra véase : STOFFEL-MuNCK, Ph., Exécution et inexécution du contrat, en 
forzada no dejó incólume a la doctrina francesa ${ }^{36}$. Para una parte de ella, la inclusión de esta excepción constituye un compromiso equilibrado entre el principio de respetar la palabra dada -fuerza obligatoria del contrato-, reflejado en la ejecución forzada del contrato y la protección del interés del deudor, que queda garantizado por la excepción del costo excesivo o irracional ${ }^{37}$. Sin embargo, una posición distinta se ha planteado, al sostener que la fuerza de la ejecución forzada está también en potenciar una facultad amplia de negociación a favor del acreedor, lo que se potencia al ser más gravosa la ejecución ${ }^{38}$. La facultad de exigir lo pactado sería fiel reflejo de lo querido por las partes, siendo un instrumento que el acreedor puede utilizar para potenciar su interés aún si opta por la indemnización de perjuicios por vía de transacción. Quedaría como límite en esta situación el abuso del Derecho, si la única causa de exigir la ejecución forzada estuviera en el interés de dañar al deudor. Esta posición constituye la visión más tradicional de la doctrina francesa, anclada en la idea que la ejecución forzada representa el respeto a la fuerza obligatoria del contrato, lo que le sitúa como la sanción principal al incumplimiento contractual.

Todavía en relación a los límites previstos a la ejecución forzada en el "Proyecto de la Chancellerie", es extraño que se haya suprimido la excepción ligada al carácter estrictamente personal de la obligación ${ }^{39}$. Sin duda es el límite tradicional y presente en la mayoría de los códigos modernos y textos internacionales ${ }^{40}$. En todo caso, la imposibilidad puede subsumir dicho obstáculo al cumplimiento forzado.

En el "Proyecto Terré" se admite como en los otros la ejecución en naturaleza o cumplimiento forzado en los artículos 105 y 106 . De alguna manera se consagra también la evolución del Derecho positivo francés, aunque la influencia del Derecho extranjero es más intensa a propósito de los límites a este remedio. A diferencia de los otros proyectos, acá se excluye la

Revue des Contrats, 1 (2009), p. 332, en particular, p. 336.

${ }^{36}$ Véase: Cabrillac, R., Le projet de réforme du Droit des contrats. Premières impressions, en Semaine Juridique, 1 (2008), p. 190 ss.; cuya respuesta fue dada por MAZeAud, D., Réforme du Droit des contrats: haro, en Hérault, sur le projet!, en Dalloz (2007), p. 2675 ss., en particular p. 2676.

${ }^{37}$ Una opinión moderada y sin compromiso en MeKki Amrani, S. - FAUVARQueCosson, B., Droit des contrats. Septembre 2007-septembre 2008, en Dalloz, 42 (2008), p. 2965 ss., en particular, p. 2968, en que se interrogan sobre el cuestionamiento que causaría la excepción a propósito de la ejecución forzada, lo que sólo podrá resolverse al conocer las decisiones de la jurisprudencia.

${ }^{38}$ Genicon, T., Observations sur le projet de réforme du Droit des contrats, en Petites Affiches, 31 (2009), p. 85 ss.

${ }^{39}$ Sobre esto, la crítica de Genicon, cit. (n. 38), p. 86.

${ }^{40}$ Ancel - Fauvarque - Cosson - Wintgen, cit. (n. 26), pp. 529 ss. 
distinción entre las obligaciones de dar, hacer y no hacer, al considerar que esa clasificación ya no constituye la directriz del cumplimiento forzado ${ }^{41}$. No se considera entre los límites a la obligación estrictamente personal, al subsumirla en la idea de imposibilidad. Al igual que el "Proyecto de la Chancellerie" se considera como límite el costo excesivo del cumplimiento forzado, aunque en forma más perfecta el "Proyecto Terré" o asocia al interés que el acreedor obtiene del contrato. Es decir, para evaluar el costo excesivo debe considerarse el interés que obtiene el acreedor de la relación contractual. En forma expresa, también, se requiere la mora del deudor, para proceder a exigir el cumplimiento forzado.

Si uno compara los tres proyectos parece más adecuado este último, pues considera la ejecución forzada en forma menos estricta. Aunque no deja de establecer una cierta primacía en su aplicación como sanción al incumplimiento contractual, los límites están bien delineados, ya sea por la idea de imposibilidad o costo excesivo. Sólo debiera considerarse la necesidad de incluir una regla dedicada al aspecto convencional de la ejecución forzada y, por otra, el límite a través de la minimización del daño como carga del acreedor en la gestión razonable que debe hacer al momento de exigir su pretensión a través de alguno de los remedios contractuales. Si uno pensara en una reforma en este ámbito, debe considerarse el lugar que ocupa la ejecución forzada entre los remedios contractuales y los límites que deben incluirse en su aplicación, considerando no sólo la imposibilidad, sino también los efectos económicos que ella conlleva y, por último, si las partes pueden en virtud de la libertad contractual excluir su procedencia o colocarla como única sanción al incumplimiento.

b) La reducción del precio. Esta otra sanción al incumplimiento contractual es extraña a las codificaciones decimonónicas, en las cuales sólo aparece un tratamiento particular, por regla general a propósito de los vicios ocultos en forma de la acción quanti minoris. Su pertinencia en una modificación a las sanciones al incumplimiento contractual es controversial, en razón que el menor valor en el precio suele demandarse a través de la indemnización de perjuicios, lo que opaca el interés de otorgarle un reconocimiento general y autónomo. El "Proyecto Terré" la incluye en el artículo 107, siguiendo los Principios europeos. (artículo 9:401). Se asemeja en cierta forma a una resolución parcial al mantenerse el contrato pero con una rebaja del precio

${ }^{41}$ Remy-Corlay, P., L'exécution en nature, en Terré, F., Pour une réforme du Droit des contrats (Paris, Dalloz, 2009), p. 264. Se sigue en esta forma de tratamiento los PEDC., artículo 9.102, los "Principios UniDroit", artículo 7.2.2 y el Marco Común de Referencia, artículo III-3:302. En estos preceptos se alude a las obligaciones no monetarias. En cambio, a diferencia de estos mismos instrumentos no se incluye una regla particular para obligaciones monetarias. 
en las hipótesis en que esto sea posible, sin perjuicio de la indemnización que pudiere proceder. Desde un punto de vista teórico aparece la reducción del precio como una sanción atractiva, mas si uno considera la resolución parcial, la viabilidad de la indemnización de perjuicios autónoma de los otros remedios, parece que su pertinencia se ve devaluada en la práctica, siendo una ventaja más sistemática que útil lo que aportaría su introducción.

c) Indemnización de perjuicios. Salvo el "Proyecto Catala" bajo la influencia de la profesora Viney, ninguno de los otros dos proyectos ha persistido en la idea de aglutinar la indemnización de perjuicios ya sea que su fuente sea un contrato o una relación entre terceros ${ }^{42}$. La regulación en el "Proyecto Terré" mantiene la inspiración del Code, en términos que la indemnización de perjuicios constituye un remedio entre otros al incumplimiento contractual, aprovechando de incluir aportes modernos y soluciones jurisprudenciales propias de la evolución del Derecho francés ${ }^{43}$. Se considera como suficiente para que se genere el Derecho a obtener indemnización de perjuicios que concurra un cumplimiento parcial, un incumplimiento total del contrato o el retardo en la ejecución, estableciendo como causal de exoneración la fuerza mayor. Para efectos del cálculo se privilegia el interés positivo debiendo colocarse al acreedor en la situación como si el contrato hubiere sido ejecutado, indicando como rubros de daños la pérdida como las ganancias no obtenidas. Se consagra, también, el límite tradicional dispuesto en materia contractual restringiendo la indemnización a los daños previstos a la época de celebración del contrato, salvo dolo o culpa grave, aunque siempre bajo la idea que dejan daños directos. La regla del artículo 120 introduce una norma interesante que puede relacionarse con la restitución por provecho del dolo, pues permite al acreedor decidir obtener del deudor todas las ganancias que haya obtenido fruto del incumplimiento. Asimismo, se recoge el deber de minimizar el daño a cargo del acreedor -artículo 121-, lo que acerca la propuesta al Derecho europeo de los contratos. Se puede observar que si bien se mantiene una arquitectura similar a aquella prevista en los códigos decimonónicos, el "Proyecto Terré" amplía la regulación introduciendo los aspectos modernos de la institución. Sin duda la propuesta del profesor Terré es la más completa, si uno considera que la idea de agrupar daños contractuales y aquellos extracontractuales es inadecuada, y al observar que el "Proyecto de la Chancellerie" omite pronunciamiento sobre la materia.

d) El cuarto remedio es la resolución del contrato; pero de él trataremos aparte.

\footnotetext{
${ }^{42}$ Véase, Catala, cit. (n. 1), pp. 189 ss.

${ }^{43} \mathrm{Remy}$, Ph., Les dommages et intérêts, en Terré, F., Pour une réforme du Droit des contrats (Paris, Dalloz, 2009).
} 


\section{El remedio de la resolución en especial.}

Sin duda la resolución se trata de una sanción principal frente al incumplimiento contractual. Existe consenso que su tratamiento no sólo en cuanto a su ubicación sino que en lo sustantivo es defectuosos e incompleto en los códigos decimonónicos. De ahí que sea necesaria una reforma integral en la materia. Asílo entienden los tres proyectos, aunque con relevantes diferencias que es necesario exponer. Entre los temas que abordan los proyectos están la inclusión de la resolución por notificación o unilateral, la resolución por anticipación, aquella convencional o cláusula resolutoria, el efecto retroactivo o marginarlo a una simple restitución en los casos que sea procedente, lo que puede explicarse a través de la distinción entre las formas de resolución y los efectos de la misma ${ }^{44}$.

a) Tipos de resolución. Si uno observa los proyectos en competencia es fácil advertir que la resolución se presenta con una forma judicial, convencional, unilateral y por anticipación. Estas manifestaciones de la resolución comprenden todas las posibilidades que han ido instalándose en el tiempo desde la época de la codificación. Se asiste a un declinación de la naturaleza judicial de la resolución posibilitando su carácter unilateral o por anticipación y considerando la facultad de las partes para organizar su procedencia y condiciones en el mismo contrato.

i) Resolución unilateral. Entre las innovaciones aparece la resolución unilateral o por notificación. El Derecho positivo francés aparece como una excepción en el concierto internacional europeo. Este sistema permite otorgar al acreedor mayores posibilidades de salirse del contrato sin tener que pasar por el tribunal. Si bien la jurisprudencia francesa después de no pocas dudas la terminó aceptando ${ }^{45}$, es imprescindible considerar en la ley sus condiciones y efectos en el tiempo. En el "Proyecto de la Chancellerie" aparece recogida en el artículo 167 , junto a aquella de naturaleza judicial y convencional. Enseguida, en el artículo 170 se consagra la regulación más precisa de esta modalidad de resolución. Para el caso que el incumplimiento prive al acreedor de su interés en el contrato se le faculta para notificar al deudor que cumpla la obligación en un plazo razonable. En esta notificación, para que sea eficaz, debe indicarse en forma clara que en caso de no ejecutarse

${ }^{44}$ Aubert de Vincelles, C., La résolution du contrat pour inexécution, en TERRÉ, F., Pour une réforme du Droit des contrats (Paris, Dalloz, 2009), p. 269 ss. Esta autora propone la exposición distinguiendo la forma y los efectos de la resolución.

${ }^{45}$ Cassacion civile, 13 de octubre de 1998, Bulletin Civil, I, No 300; Jamin, C., Observations, en Dalloz, (1999), p. 197. Aparece también recogida esta facultad en el artículo 349 BGB.; artículo 7.3.1 de los "Principios UniDroit"; artículo 9:301 de los PEDC.; y el artículo 114 del "Código Gandolfi" o "Proyecto de la Academia de Pavia”. 
la obligación el acreedor podrá resolver el contrato. Para hacer efectiva la resolución si persiste el incumplimiento, el acreedor deberá notificar la resolución del contrato junto con las razones que la justifican, entendiéndose resuelto el contrato desde la recepción de la notificación. En el "Proyecto Catala" que sirvió de fuente en esta parte al de la Chancellerie se afirma también la necesidad de colocar en mora al deudor junto a un plazo para que satisfaga la obligación. La idea de considerar un plazo para el cumplimiento $y$, por ende, la mora, puede tener dos justificaciones. Ya sea que se quiere dar una última oportunidad al deudor para ejecutar su obligación o, en cambio sólo se le está permitiendo organizar el término del contrato ${ }^{46}$. Más bien la conclusión que se puede extraer en los tres proyectos, que contemplan la necesidad de la mora y el plazo de gracia para la ejecución, es todavía permitir la ejecución del contrato. Un argumento sostenido para ratificar esta posición ha sido que aún en el ámbito convencional a través de las cláusulas resolutorias expresas es usual contemplar la necesidad de colocar en mora al deudor para que ejecute la obligación. Esto contrasta con los "Principios Unidroit" y los PEDC., pues en éstos no se exige mora para la eficacia de la resolución unilateral. Si bien puede aceptarse como válido el argumento de la práctica usual en los contratos a través de la cláusula resolutoria, es cierto que en algunas ocasiones ya no hay nada que hacer, pues el cumplimiento carece de valor para el acreedor, éste es imposible o resulta urgente la ejecución.

En cuanto a la motivación de la resolución unilateral, por una parte el "Proyecto Catala" y aquel de la Chancellerie justifican la necesidad de informar al deudor las razones por las cuales el acreedor ha puesto término al contrato, mientras que el "Proyecto Terré" ha excluido esta condición, en razón que esto podría generar un contencioso ingente en relación a la pertinencia de dichos fundamentos, optándose más bien por alterar la carga de la prueba, dejando en caso de contestación judicial de la resolución en manos del acreedor probar que la resolución se justificaba ${ }^{47}$. Esta última alternativa parece más razonable, pues aún en el caso que el deudor controvierta la decisión del acreedor por vía judicial siempre deberá revisarse la motivación, agregando una formalidad inútil al exigirse en la notificación. Esta posibilidad de cuestionar la resolución unilateral está abierta al deudor en todos los proyectos, aunque la sanción en caso de inapropiada resolución no es uniforme. Las alternativas si el deudor obtiene una sentencia positiva son que se ejecute el contrato en los términos previstos o que se resuelva de igual manera con indemnización de perjuicios. En razón que los procesos judiciales pueden tomar bastante tiempo para alcanzar una sentencia que otorgue razón al

\footnotetext{
${ }^{46}$ En este sentido lo explica Aubert de Vincelles, cit. (n. 42), p. 271.

${ }^{47}$ Aubert de Vincelles, cit. (n. 42), p. 272.
} 
deudor parece más razonable que ambas posibilidades estén presentes, siendo función del juez sobre todo evaluar la pertinencia de una ejecución cuando ya ha transcurrido bastante tiempo desde el inicio de la relación contractual. En los tres proyectos puede llegarse a esta interpretación.

ii) Resolución por anticipación. Ausente en el "Proyecto Catala" la posibilidad del acreedor de colocar término al contrato antes del incumplimiento aparece recogida en el "Proyecto de la Chancellerie" y en el "Proyecto Terré”, así como en la mayoría de los instrumentos internacionales ${ }^{48}$. Su pertinencia fue discutida al estimar que el acreedor quedaba con demasiados poderes para evaluar en forma discrecional el futuro incumplimiento. Sin duda se fragiliza la idea que los contratos se hacen para cumplirse, ya que un acreedor temeroso o conservador podría preferir salir del contrato antes que asumir riesgos en caso de una situación delicada del deudor. Además, esta resolución unilateral si bien puede ser controvertida por el deudor, no siempre tendrá los medios económicos para hacerlo, pudiendo generar un abuso de la parte del acreedor a partir de esta facultad ${ }^{49}$. Estos temores no son justificados dado que el deudor en todo caso podrá justificar su idoneidad para cumplir con sus obligaciones y discutirlo siempre ante un tribunal. La diferencia entre el "Proyecto de la Chancellerie" y el "Proyecto Terré" radica en que en el primero no está en forma explícita la facultad del acreedor de solicitar al deudor garantía de que cumplirá con su obligación en caso de sospechas y sólo en ese caso podrá proceder a poner término anticipado al contrato. El "Proyecto de la Chancellerie" otorga la facultad de resolver en forma anticipada sin considerar esa condición. Es más perfecto el "Proyecto Terre" al otorgar una oportunidad al deudor de asegurar el cumplimiento del contrato. Cumplida esta condición el acreedor podrá proceder a la resolución notificando su intención.

iii) Resolución judicial. En relación a la resolución juridicial existe un amplio consenso en los proyectos, pues se recoge ampliamente el estado actual de la cuestión en la jurisprudencia. Por ende se trata de un ámbito en que las propuestas no sólo coinciden, sino que no innovan en gran medida. Se sitúa entre los distintos remedios a favor del acreedor, se consagra la posibilidad de obtener la resolución parcial del contrato para el caso que la ejecución sea divisible ("Proyecto Catala", artículo 1160; "Proyecto Terré", artículo 114); si bien no en todos se hace mención a la necesidad de un incumplimiento grave, aparece esta condición en el "Proyecto Terré" en términos generales

${ }^{48}$ Artículo 9:304 de los PEDC.; artículo 7.3.3 de los “Principios UniDroit” y artículo 73 de la "Convención de Viena".

${ }^{49}$ Aubert de Vincelles, cit. (n. 42), p. 273. 
para todo tipo de resolución (artículo 108), aunque esta idea está bien asentada en la jurisprudencia y doctrina francesas.

En todos los proyectos se recoge la resolución por vía judicial otorgándose un lugar privilegiado en razón que en todo caso podrá demandarse, según dispone el artículo 172 del "Proyecto de la Chancellerie", artículo 110 inciso final del "Proyecto Terré" y artículo 1158-1 del "Proyecto Catala". Destaca en el "Proyecto Terré" la posibilidad de invocar la resolución judicial aún en la hipótesis en que esté ya en curso la resolución por notificación o por anticipación. Persiste un cierto privilegio a la resolución judicial. Sin embargo, la introducción de la resolución anticipada y la resolución unilateral, ambas con un fundamento económico, permiten un Derecho de los contratos más ágil que traslade al deudor que se supone incumplió o se cree que incumplirá la carga de reclamar ante los tribunales de justicia.

b) Efectos de la resolución. Tal como se ha ido instalando en otros sistemas legales europeos, el "Proyecto Terré" opta por suprimir el efecto retroactivo de la resolución ${ }^{50}$. Asumiendo una crítica constante a la falsedad de ese efecto retroactivo similar a aquel una vez declarada la nulidad, el "Proyecto Terré", apartándose de los otros dos, suprime el efecto retroactivo de la resolución. Dicho efecto retroactivo es más ilusorio que real, aún más en Derechos en que se realiza la distinción entre el título y el modo y al considerar determinadas cláusulas del contrato que aún produciéndose la resolución perviven. Basta mencionar la cláusula arbitral, cláusulas limitativas o exonerativas de responsabilidad, la cláusula penal o aquellas de atribución de competencia. La ficción del efecto retroactivo es aún más patente tratándose de los contratos a ejecución sucesiva. De ahí que las consecuencias o efectos de la resolución se traslade a un asunto de restitución, pero ahora en forma independiente de la retroactividad. Dichas restituciones tendrán lugar para el evento en que sólo una de las partes haya ejecutado su obligación sin recibir la prestación recíproca. Otra novedad en el "Proyecto Terré" consiste en relacionar las restituciones a las reglas relativas a la repetición de lo no debido.

\section{ConClusión}

Las líneas precedentes permiten concluir que el Derecho francés si bien con una parte de su doctrina aún maravillada con su código (tal cual acontece en el "Proyecto Catala"), persiste en la idea de rigidizar las fronteras de su Derecho, nada más proponiendo maquillar el Derecho de las obligaciones

${ }^{50}$ Ancel, P. - Fauvareue-Cosson, B. - Wintgen, R., cit. (n. 26), p. 543 ss.; Aubert de Vincelles, cit. (n. 42), p. 274 ss. 
con una adaptación a la evolución jurisprudencial, los otros dos Proyectos, se abren a la influencia del Derecho de los contratos plasmados en instrumentos internacionales sobre la materia, en particular, los "Principios Unidroit" y los PEDC., lo que potencia la irradiación que podría tener aún el Derecho francés en otras latitudes. El debate es rico en ideas y propuestas sobre las diversas cuestiones que atañen al incumplimiento y las sanciones al mismo, donde se confrontan aspectos vinculados a los principios y otros de índole económica. La necesidad, en todo caso, de avanzar en una modificación está ya bastante aceptada, siendo la técnica, estructura y opciones jurídicas el centro de la discusión. En nuestra opinión el proyecto más perfecto es aquel plasmado en el trabajo del grupo de profesores liderados por François Terré. No sólo por su apertura a nuevas instituciones que hacen más funcional, accesible y práctico el Derecho de los contratos al justiciable, cuestión que comparte con el "Proyecto de la Chancellerie", sino por su redacción, coherencia y técnica jurídica. Es imposible saber si alguno de estos Proyectos dará lugar a una reforma legislativa, pero sin duda constituyen un insumo valioso para el estudio de procesos de reforma en países de América Latina en que el Derecho francés tuvo tanta influencia.

\section{BiBLIOGRAFÍA}

AA. VV., Le Code Civil 1804-2004, Livre du Bicentenaire (Paris, Dalloz-Litec, 2004). AA.VV., 1804-2004, Le Code Civil, un passé, un présent, un avenir (Paris, Dalloz, 2004).

Ancel, P. - Fauvarque-Cosson, B. - Wintgen, R., Regards comparatistes sur l'exécution forcée en nature, en Revue des Contrats, 2 (2006).

Aubert de Vincelles, C., La résolution du contrat pour inexécution, en Terré, F., Pour une réforme du droit des contrats (Paris, Dalloz, 2009).

CABRILlaC, R., Le projet de réforme du droit des contrats, en La semaine Juridique, édition générale, 40 (2008), I.

Cabrillac, R., Le projet de réforme du droit des contrats. Premières impressions, en Semaijne Juridique, 1 (2008).

Catala, P., Avant-projet de réforme du droit des obligations et de la prescription (Paris, Ministère de la Justice, La Documentation Française, 2006).

Díez-Picazo, L., Reforma de los Códigos y Derecho europeo, en Anuario de Derecho Civil, 56 (2003) 4.

Díez-Picazo, L., - Roca Trias, E. - Morales, A. M., Los principios del Derecho europeo de contratos (Madrid, Civitas, 2002).

EBERs, M., La nueva regulación del incumplimiento contractual en el BGB, tras la Ley de modernización del Derecho de obligaciones de 2002, en Anuario de Derecho Civil, $56(2003) 4$.

Genicon, T., Observations sur le projet de réforme du droit des contrats, en Petites Affches, 31 (2009).

GHestin, J. y otros, Observations sur le projet de réforme du droit des contrats, en Petites Affiches, 31 (2009). 
Ghozi, A. - Lequette, Y., La réforme du droit des contrats, en Dalloz, 37 (2008).

GRIDEL, J. P., Les sanctions civiles de l'inexécution du contrat imputable au débiteur: état des lieux, en Semaine Juridique, 21 (2008) 1.

GRIMALDI, M., El Derecho continental frente a la mundialización (traducción castellana de Sara Moreno), en Pizarro Wilson, C. (editor), Derecho y Economía. Cátedra por el Derecho Continental (Santiago, 2011) (en prensa).

Grimaldi, M., L'exportation du Code Civil, en Pouvoirs. Revue Française d'études Constitutionnelles et Politiques, 107 (2003) [disponible en http://www.revue-pouvoirs. $\mathrm{fr} / \mathrm{L}$-exportation-du-Code-civil.html, visitada el 3 de enero de 2011].

Jamin, C., Observations, en Dalloz, (1999).

Jestaz, Ph. - Jamin, C., La doctrine (Paris, Dalloz, 2003).

Jourdain, P., Présentation des dispositions de l'avant-projet sur les effets de la responsabilité, en Revue des Contrats, 7 (2007) 1.

LAITHIER, Y. M., Étude comparative des sanctions de l'inexécution du contrat (Paris, LGDJ, 2004).

LAITHIER, Y.-M., L'exécution des obligations contractuelles, en CARTWRIGHT, John Vogenauer, Stefan - WhitTAKeR, Simon, Regards comparatistes surl'avant-projet de réforme du droit des obligations et de la prescription (Paris, Société de Législation Comparée, 2010).

Lequette, Yves, D’une célébration à l'autre (1904-2004), en Université Paris II Panthéon-Assas (editor), 1804-2004 Le Code Civil, un passé, un présent, un avenir (Paris, Dalloz, 2004).

Lequette, Yves, Vers un Code Civileuropéen? en Pouvoirs, en Revue Française d'Études Constitutionnelles et Politiques, 107 (2003) [disponible en http://www.revuepouvoirs.fr/Vers-un-Code-civil-europeen.html, visitada el 3 de enero de 2011].

Malaurie, Ph. - Aynès, L. - Stoffel-Munck, Ph., Les obligations (Paris, Defrénois, 2009).

MAZEAUD, D., La réforme du droit français des contrats : trois projets en concurrence, en Liber amicorum Christian Larroumet (Paris, Economica, 2009).

Mazeaud, D., Réforme du droit des contrats: haro, en Hérault, sur le projet! en Dalloz (2007).

Mekni Amrani, S. - Fauvargue-Cosson, B., Droit des contrats. Septembre 2007septembre 2008, en Dalloz, 42 (2008).

Pascal, Ancel y otros,, Points de vue convergents sur le projet de réforme du droit des contrats, en Semaine Juridique, 48 (2008) 1.

Pizarro Wilson, C., En defensa de la Dogmática: los civilistas hoy, en Carvajal, Patricio (editor), Libro homenaje a Alejandro Guzmán Brito (2011), en prensa.

Pizarro Wilson, C., Hacia un sistema de remedios al incumplimiento contractual, en Guzmán Brito, Alejandro (editor científico), Estudios de Derecho Civil (Santiago, LexisNexis, 2008), III,.

Propuesta de Modernización del Código Civil en materia de obligaciones y contratos, en Boletin de Información (Madrid, Ministerio de Justicia, 2009).

Remy, Ph., Les dommages et intérêts, en Terré, F., Pour une réforme du droit des contrats (Paris, Dalloz, 2009).

Remy-Corlay, P., L'exécution en nature, en Terré, F., Pour une réforme du droit des contrats (Paris, Dalloz, 2009).

Stoffel-Munck, Ph., Exécution et inexécution du contrat, en Revue des Contrats, 1 (2009). 
Tallon, D., Grandeur et décadence du Code Civil français, en Mélanges Marcel Fontaine (Paris, Larcier, 2007).

TAllon, D., Les principes pour le droit européen du contrat, en Défrenois (2000).

Tallon, D., Vers un droit européen du contrat? en Mélange A. Colomier (Paris, Litec, 1993).

TALlON, D., L'inexécution du contrat: pour une autreprésentation, en Revue Trimestrelle de Droit Civil. (1994).

Terré, F. - Simler, Ph. - Lequette, Y., Droit civil. Les obligations (Paris, Dalloz, 2005).

Terré, F., Pour une réforme du droit des contrats (Paris, Dalloz, 2009).

Vidal Olivares, A., El incumplimiento de obligaciones con objeto fungible y los remedios del acreedor afectado. Una relectura de las disposiciones del "Código Civil" sobre incumplimiento, en Guzmán Brito, A. (editor) El Código Civil de Chile (18552005). Trabajos expuestos en el congreso internacional celebrado para conmemorar su promulgación. Santiago, 3-6 de octubre de 2005 (Santiago, LexisNexis, 2007). 